\title{
Understanding Workplace Harassment -Its Varying Types and Consequences
}

\author{
Flourish Itulua Abumere \\ University of Central Nicaragua School of Public Health and Social Work Managua, Nicaragua
}

\begin{abstract}
Workplace harassment has lately attracted the attention of scholars and workplace investigation experts as one of the most vital spots of efficient organizational management, because intimidating workplace behaviors are an important element of employee stress. Workplace harassment is one of the most neglected issues by managers in African countries. Notwithstanding, it has attracted the attention of academics and government bodies since the 1980s. Workplace harassment in this article review is identified as a fundamental organizational stressor and in other occupational health and safety legislation across the globe. Workplace harassment includes excessive monitoring, harsh criticism, practical jokes, unfairly altering job responsibilities and obstructing promotions. This article critically introduced some types of workplace harassment and their consequences for employees and employers.
\end{abstract}

Keywords: Workplace, harassment, harsh criticism, practical jokes, verbal abuse

\section{INTRODUCTION}

$\mathrm{H}$ arassment in the workplace refers to insulting or abusive, inappropriate behavior, physical assault directed against a single employee or a group of employees (Williams, 2001).

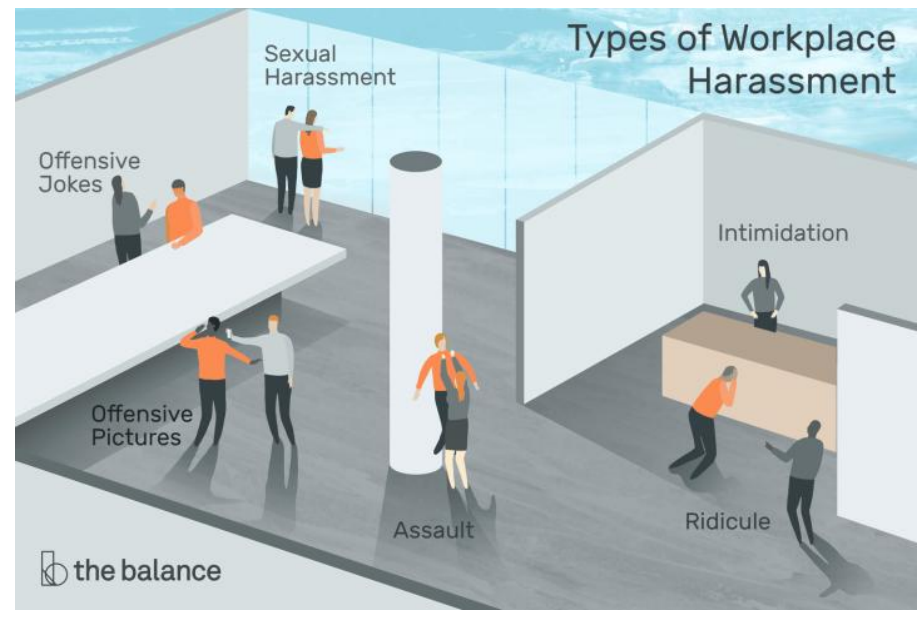

(The Balance Careers, 2021)

Workplace harassment has recently piqued the interest of practitioners and scholars since it is quickly becoming one of the most critical parts of successful workplace management, as aggressive actions at work are a substantial source of work stress (Tehran, 2004). Workplace harassment is one of the concerns that managers in Asian countries pay little attention to (Rokonuzzaman and Rahman, 2011). Since the 1980s, however, it has piqued the interest of researchers and governments. Workplace harassment and bullying are designated as core psychosocial risks in occupational health and safety laws around the world (WHO 2009). (Production Commission, 2010). Workplace harassment includes overbearing supervision, continuous criticism, and denial of advancements (de Las Casas, 2018).

Violence, harassment, and abuse in the workplace, particularl $\mathrm{y}$ against women, are prevalent all around the world (Krieger et al., 2006). According to statistics, up to $50 \%$ of American women face sexual harassment in the workplace (Das, 2009), although only a small percentage of them disclose this extreme form of intimidation (Feldblum and Lipnic, 2016). Workplace harassment and frustration have been linked to mental health problems, including sleep difficulties, melancholy, nervousness, PTSD symptoms, and emotional distress, according to studies (Gunnarsdottir et al., 2006; Nabe-Nielsen et al., 2016).

This can be true even for colleagues and teammates who aren't immediately affected (Di Marco et al., 2016, 2018). Work related stress has also been linked to an enlarged incidence of muscle strains and disorders, as well as a greater cardiovascular disease risk (Gale et al., 2019). According to Gate et al., the current mechanisms have proven to be ineffective in preventing workplace abuse (Fitzgerald, 1993; Okechukwu et al., 2014; Burke and Cooper, 2018). Victims are constantly left without help, either from their employers, society or from physicians, as they navigate the aftermath of these events. Although evidence suggests that workplace violence such as sexual harassment early in a career has longterm impacts on depressive symptoms, which can affect quality of life, friendships, and career and economic attainment, just a hand full of research has looked into the longitudinal strip effects of workplace abuse (Houle et al., 2011).

Workplace harassment has the potential to harm organizations by lowering employee morale, effectiveness, constant absences, gross revenue, organizational dedication, and the employer's external reputation (McDonald et al., 2015). Efficient organizational harassment and abuse avoidance 
requires a thorough examination of the present context, which includes offender characteristics, worker profiles (for example, age, gender, race, ethnicity, sexuality), and the time when the harassment took place. Clear business rules that offer workers and supervisors with appropriate instructions, guidelines, and training and authorized instruments to address abusers are among the prevention techniques (Fitzgerald, 1993; Okechukwu et al., 2014; McDonald et al., 2015).

\section{Preliminary studies}

Previous research indicates that a lot more people are subjected to perpetual oppressive labor practices (Keashly and Harvey 2006), with research conducted in Europe suggesting that between 10 and 15 percent of the workforce is subjected to workplace harassment (Zapf et al. 2020), and North American research clearly shows comparable prevalence estimates (Keashly and Jagatic 2011). Nevertheless, the definition of workplace harassment determines how one can identify or claim workplace harassment is happening or taking place. The claimed frequency of workplace harassment may differ considerably. While some researchers define harassment as actually happening if the victim has encountered aggressive behaviors from the abuser at least once or twice a week for six months (e.g., Leymann 1996), some even define harassment as defined previously if the victim has experienced negative behaviors less frequently and for a shorter period of time (e.g., Zapf et al. 2011, for example). According to Einarsen et al., (2020), this is a major and continuing issue for academics and practitioners, and reaching a consensus on ways to solve this problem has never been easy or straight forward, although it would be advantageous due to the legal and policy consequences (Nielsen et al. 2011; Einarsen et al. 2020) for both employees and employers.

Notwithstanding, considerable study has been conducted into the characteristics of individuals who may be more at increased danger of becoming the subject of workplace harassment. According to Zapf et al. (2011), the vast majority of research has concentrated on downward harassment (as aided and abetted by managers against subordinates), to a slightly lesser degree, on horizontal harassment (as perpetrated by one colleague against another), and, more importantly, on upward harassment (as incited by an employee against someone in a management position). This means that harassment may happen at any level inside an organization. Additionally, despite the fact that workplace harassment may be more prevalent in certain sectors (Hubert and van Veldhoven 2001; Zapf et al. 2011), workplace harassment may occur in almost every company or industry (Lewis and Gunn 2007).

A dynamic theoretical framework is needed to explain a phenomenon as complicated as workplace harassment so that organizations may eventually minimize and/or engage in the critical aspects of preventing these kinds of abuses. Studies in the field of workplace harassment have lacked a solid theoretical foundation (Einarsen 2000). 'We have yet to explain the phenomena with a complete theory,' according to Wheeler et al. (2010 p. 554). A few models in the academic space have been used to examine important aspects of workplace harassment research, such as leading causes, starting, and impacts on well-being.

(Nielsen, 2013; Schütte et al., 2014) found that workplace harassment was a negative psychological predictor of psychiatric problems and sick day increment. It has also been noted that workplace harassment is a fairly dangerous workrelated predictor of poor sleep (Niedhammer et al., 2013; Nielsen et al., 2018). The scenario of workplace harassment, whereby an employee is subjected to harassment and nonphysical maltreatment at work on a consistent and systematic basis over an extended length of time, and in which the victim finds it hard to protect themselves against the abusers, has placed this problem as one of the most critical issues employees face in the workplace (Einarsen et al., 2020). If you compare workplace harassment to other kinds of more accidental maltreatment at work, such as incivility and physical assault, workplace harassment is a form of continuous and repetitive psychological aggression where the victim finds it hard to resist abusive harassment (Einarsen et al., 2020).

Harassment is not an "either/or phenomenon," but rather a progressively increasing process in which the victim is constantly more impacted and traumatized as a result of his or her interactions with the harasser. The occurrence of workplace harassment is estimated to be as high as 15 percent of employees at any one moment, according to the most recent data (Nielsen et al., 2010). Working conditions that are harassing lead to poor mental and physical health (Verkui et al., 2015), post-traumatic stress disorder, decreased job satisfaction and organizational commitment, and a higher likelihood of employee absenteeism, according to many metaanalytic reviews of cross-sectional and prospective studies (Nielsen et al., 2016). Also, plausible is the expectation that exposure to harassment enhances the probability of sleep difficulties, and that sleep disturbances are a channel via which harassment effects on other aspects may be explained. As shown by results on abnormalities in cortisol regulation among harassed employees (Hansen et al., 2011), harassment has an effect on levels of arousal and promotes physiological activity to last for an extended period of time. According to the cognitive activation hypothesis of stress, cognitive activation is a critical component in the cycle of emotional and physiological arousal that occurs during stressful situations. Sleep problems such as insomnia, for which psychosocial stress is considered a typical triggering variable (Spielman et al., 1987), and hyperarousal (Bonnet \& Arand, 
2010) are considered a characteristic of the disease (Bonnet \& Arand, 2010).

\section{TYPES OF WORKPLACE HARASSMENT}

Practical Jokes: Pranks, jokes, and stunts in the workplace are not amusing. Inappropriate behavior by employees can result in a slew of frustrations followed by harassment claims filed against employers. It is critical that the workplace be both secure and freely accept multiculturalism. Trying to play stunts on stressed-out coworkers will almost certainly result in workplace conflicts and lawsuits. The employment tribunal case of Hurley v East Sussex Healthcare NHS Trust (HM Courts \& Tribunals Service \& Employment Tribunal, 2021) serves as an excellent cautionary tale to employers of the importance of having a clear guideline for acceptable conduct for their workers. It is simply inappropriate to manipulate or deceive an already stressed or exhausted employee to prepare for a bogus, falsified presentation. As the judge in Carol Hurley's case put it, 'it was not at all funny, like many practical jokes'. Practical jokes are rarely unfortunate examples; rather, they are observed to be part of a collection of occurrences, oftentimes complemented by intimidation and further ostracization. Victims who traditionally file concerns, such as Carol Hurley, have their concerns turned down almost instantaneously or after a sham investigation. Discipline in the workplace should be one of the primary solutions to practical jokes.

The case of Carol Hurley (HM Courts \& Tribunals Service \& Employment Tribunal, 2022) is not a revolutionary case, but it does present a strong caution to employers who are relaxed

with their rules concerning this subject matter and how this ki nd of behavior might result in wrongful termination allegations. There have been several cases when practical jokes have resulted in winning employment tribunal suits (Lockwood, 2008; Ashe \& Nazroo, 2016). However, in today's atmosphere, where many workers are working under increasing stress and tension, it is much more crucial than ever before for firms to give out a strong and consistent message about proper workplace behavi or. It's not just about avoiding costly lawsuits when you promote a consistent and healthy workplace culture. A weak work culture can result in a variety of problems, including underperformance, high absenteeism, job dissatisfaction, resentments and discrimination claims, difficulty attracting, hiring, and retaining staff, and a ruined public image. The workplace culture percolates down to the rest of the employees. Changing a workplace's culture is a difficult process. Developing a positive culture necessitates commitment, verifiable moral behavior from management and supervisors, and a zero-tolerance policy for bullying and harassment (Wagner \& Hollenback, 2020).
Unfairly altering labor responsibilities: Bullying in the workplace poses a significant risk to the health, human security, and wellbeing of employees and can take place in any setting. Intentionally altering work schedules in order to cause annoyance to specific employees is a psychologically stressful practice that can be used to intimidate or oppress an employee (Weinberg et al., 2010). Workloads and/or work schedules that are assigned in an unfair manner are a form of harassment. For example, mandating a specific woman to stay behind after a long shift or redeploying them to overnight shifts on a consistent basis are both examples of abuse. It is important to note that, in cases where the requirements are reasonable, redeployment and distributing of working hours are not considered harassment. This is a completely different situation. When subordinates purposefully or negligently overwhelm an individual with work or fail to provide enough work, it is a signal of rising issues and complaints (Quigg, 2016). Among the other signs of this are unjustifiably setting deadlines which are tough to meet or frequently changing deadlines that are not necessary, delegating work that is excessively beneath or above a person's personal level of skill, intentionally exempting, segregating, or belittling an employee from receiving certain message communications that everyone is entitled to, or interfering with standard work operations, such as excluding an employee from a meeting or danger warning (Lutgen-Sandvik \& McDermott, 2008).

Continued denial of requests: When it comes to requests from their superiors, the majority of employees try to be as supportive as possible. Among other things, they will take on additional work, complete work that is not specified in their job role, and even participate in activities that conflict with family obligations. In one's professional life, however, there really are times when saying "no" to your manager is absolutely necessary, particularly if your manager is a harasser. It goes without saying that facing your manager is not even an easy decision. It could also be a frightening experience for some. The strength of character to do just that singular act, on the other hand, may contribute to making your workplace satisfaction and achievement a reality in the future. In actuality, studies suggest that responding actively or boldly to bullied workers may help them feel less mistreated (Aquino \& Thau, 2009).

Employees who advocate for themselves not only feel less like victims, but they also usually feel more satisfied with their jobs and much more fulfilled, generally speaking, according to research conducted by researchers at Ohio State University and the University of Georgia (Tepper et al., 2015). The study also discovered that they did not experience the same effect on psychological anguish as someone who simply takes the abuse without challenging it (Tepper at al., 2015). It is important to understand that before an employee confronts their manager or superiors, they should consider whether the issue is one that warrants fighting 
back on. Depending on the situation, you might just want to wait and see how things develop. However, there are some situations in which you should not embrace your boss's mistreatment or consider giving in to their unnecessary demands. Keep in mind, no matter how much one relies on their job, you must be able to recognize when an abuser has stepped over the line.

It is important to be aware that workplace stress can have serious implications, and could even have a detrimental effect on one's personal life and family life if it is continuous and becomes even more severe and systematic (Giorgi et al., 2016). You should keep in mind that the implications of someone doing something they don't agree with can lead to distress. For employers, aside from the fact that it will have an adverse effect on your business public image, you may also encounter health problems as a result of stress from the problems that accompany such an act. Employees who are victims can develop illnesses as a result as well. Such as developing ulcers, experiencing anxiety, and even experiencing sleep deprivation (Killoren, 2014). In general, it is never a good idea to make concessions to your personal values at work. Always find a common ground.

Threats, humiliation, and other verbal abuse: Bullying, humiliation, and other forms of psychological/emotional harassment include swearing or verbal abuse. Other forms of psychological/emotional abuse include coercion, harassment, and the use of threats. The fact that it occurs in the workplace does not make it any easier. When an individual is subjected to undue influence in the course of managing or supervising another individual in the workplace, this can result in intense forced pressure. When people make verbal threats, they sometimes do so with the genuine intention of hurting or embarrassing others, and they are almost always directed at someone in the workplace specifically. Verbal threats gain strength and validity when they are accompanied by disturbing expressions. Making the threat of slapping someone in the face with a mallet is going to come across much more dangerously to the other person. Obviously, being attacked verbally by a coworker is not uncommon. However, an immediate and appropriate immediate reaction can ensure that the harassment is brought to a close (Johnston, 2017).

One thing that needs to be considered about threats as well as other types of harassment is that they become concerning when a colleague continues to threaten to hurt or kill another coworker, most likely as a result of an argument or even without one. In addition to the person speaking damagingly with precise and irrefutable statements, the receiver should have a reasonable suspicion and despair that the person speaking will carry out their threat; and the oppressor most likely communicates the threat orally, in writing, or through electronic correspondence (for instance, via email, text message, etc.). When these aspects manifest themselves in such a situation, it suggests that a verbal threat is substantial, and a person has the right to file a criminal complaint for direct assault. Coworkers who are threatened have the responsibility to report the incident to the authorities if the human resource department is unable to rectify the issue internally, who will then file an incident report (Wishnia, 2020).

A person who commits a verbal attack can face a variety of legal repercussions. Paying criminal penalties, being placed on probation, and paying compensatory damages are just a few examples. Because somebody hasn't been found guilty doesn't mean they won't be fined and arrested for harassing. When an offender makes frequent, impolite, harsh comments that involve verbal abuse, the assaulter may be arrested for his or her actions. An individual may also be sentenced to prison for making verbal threats. It is a wise decision to choose the words you say to coworkers. This is why continuous professional training is encouraged at workplaces (Wishnia, 2020).

Verbal abuse has the potential to cause significant psychological harm (Zafar et al., 2016). Devastation from verbal abuse is often concealed despite damaging the victim psychologically, particularly when professionals interact with the public and are normally conscious of how they conduct themselves. Even when the honor of the receiver is violated, they will try not to retaliate. Anxiety, a loss of attention, decreased motivation, and perhaps even despair may arise as a result of this. Furthermore, verbal abuse has the potential to sabotage strong working relationships and degrade the workplace atmosphere. Physical aggression and hostility may result in more serious situations. Absenteeism, resignation, extreme dissatisfaction, as well as lower efficiency and effectiveness, are all repercussions of a deteriorated workplace atmosphere in which workers speak their minds, hurl obscenities and invectives, and verbally vent their frustrations. Harassment can be expensive in terms of time and resources squandered. Disparaging comments, hooting, insolence, ridicule, reprimands, reproaches, rumors, sarcasm, scolding, screaming, swearing, teasing, whispering, and yelling are only a few types of threats and verbal abuse (Chin \& Yi, 2019).

Excessive performance monitoring: The practice of assessing a workplace environment for continuous training and development is known as performance monitoring. It will be accomplished by sustaining employee performance and developing individual capabilities in order to increase organizational productivity (Albrecht et al., 2015). Successful business management necessitates continuous performance monitoring in order to provide feedback with which to assess the strength or weakness of specific strategies. In the implementation of performance monitoring, the management assesses the performance of the employees using periodical 
written reports, scheduled meetings, on-the-spot assessments, or field visits in the event of employees who work in locations other than the manager's. Throughout the monitoring process, the management delivers feedback to the employees and invites them to provide comments during team discussions. Individualized meetings are held to address specific difficulties and problems that individual employees are experiencing. Following that, the manager and the staff discuss the necessary measures, which can be implemented by any or both of them (Aguinis, 2019).

Employee and manager acceptance of shared effort for tracking performance on objectives and responsibilities consented upon during the expected performance scheduling and subsequent review meetings is precisely promoted through the process of performance monitoring (Armstrong, 2021). To ensure that objectives and expectations are completed quickly and with great quality, managers use a variety of tools, such as written reports, review meetings, and on-the-spot inspections. When lawfully required by the manager's tasks, including those decided upon during planning and evaluation meetings, assistance and support should be provided. Introducing the continuous learning and development process in order to improve employee job performance as well as strategies and procedures for measuring performance is perfect (Bititci et al., 2016). Performance managers benefit from regular reviews as well, but not excessive ones. A normal review can help with monitoring and encouragement of progress, in order to keep the work on track (Tomczak et al., 2018).

Since it has been established that performance monitoring is important for a variety of reasons, including having a strong continuous performance appraisal system, assisting in the alignment and tracking of desired outcomes, creating a continuing virtuous cycle for training, and increasing employee engagement through acknowledgment, it is critical to recognize that there are also clear downsides to excessive performance monitoring. Inordinate, unnecessary performance monitoring can be perceived as harassment if the situation is severe enough. Employers frequently find themselves in such a difficult situation when having to deal with underperformers and deciding whether or not to enroll them in a performance management system. The ability of these actions to be viewed as reasonable strategic decisions in response to unsatisfactory performance is critical. Large and major corporations, labor advocacy groups, legal experts, liberal activists, academics, economists, professional sociologists, and many others have expressed concerns about performance monitoring. Every critic has their own socioeconomic, constitutional, or moral reasons for or against employee monitoring, also referred to as performance management (Martin \& Freeman, 2003).

Employers are not expressly forbidden from improving the performance of employees who they believe are functioning below expectations. That being said, caution must be exercised in order to avoid harassing a member of staff. What is it about excessive performance mentoring that makes it so bad? Excessive performance monitoring can limit the ability to be flexible in the execution of tasks. In response to the question above, it reinforces the idea of a theocracy in the place of business. In fact, according to the results of research conducted by Holman et al. (2002), excessive monitoring is portrayed as intimidating when it is carried out in an excessive manner. The premise is that the stronger the intensity of monitoring, the higher the chance that people will work to comply rather than out of pure commitment and initiative to do so. Excessive monitoring can cause one's employees to become extremely self-conscious about their every step, causing them to become unproductive in reality. It indirectly prompts the performance to be inviolable, which implies that there really is no room for error on the part of the employee. Such practice in a workplace environment is too extreme and shouldn't be overlooked (Clark \& Beck, 2011).

"What is the point of working if I am unable to make my own decisions?" If, unexpectedly, the workplace appears to be a prison, then there is no point in continuing to work on a reasonable scale, according to (Rodela, 2015). Workers' ability to make independent decisions is reduced when they are absolutely sure that they are under surveillance from all angles. As a result of this, positive attitudes, innovation, and competence are all diminished. Furthermore, as a manager or business owner, you don't want that to happen. You would rather choose to cultivate workers who are self-assured, innovative, skillful, and competent, and who can be trained to become the best and brightest. As a result, it will be a wiser decision to engage them instead of acting as a bully. Allow employees you fully know are not underperforming to think for themselves rather than simply carry out their responsibilities. It is indispensable for employees to believe that they can be trusted to deliver the results that are expected of them. Escalating tensions by closely monitoring an employee's performance will do absolutely nothing to help the performance itself. It even has the effect of limiting the growth potential of your workers (Hollenbeck \& Jamieson, 2015).

The fact of the matter is that monitoring loses its usefulness when it serves to bring your staff ridiculously low rather than to lift them. Some managers prefer to be overly investigative in their work. These leaders place unrealistic expectations on their colleagues and expect quick results to be delivered right in front of their faces (Zhao et al., 2016). The workplace should be accommodative to new skills with the willingness to learn even better ones, but when this is impossible due to excessive performance monitoring, it becomes discriminatory. Recognize that employees already have a wealth of talents, education, and sometimes experience; otherwise, you would not have hired them in the very first place. Performance 
monitoring should be carried out with the goal of building this reservoir in mind, rather than simply pinpointing any shortfalls. Don't spend too much time thinking about the minor errors employees make. Concentrate on whether you can tackle these issues in order to achieve continuous progress (Amabile \& Kramer, 2011).

Overly harsh or unjust criticism: In the course of a career, almost everyone will be subjected to harsh criticism. Harsh or unfair criticism can make an employee feel belittled, annoyed or completely misinterpreted as a result of this. As stated by Grenny (2014), "Critical feedback is traumatic because it threatens two of our most fundamental psychological needs: safety (perceived physical, social, or material security) and worth (a sense of one's own worth, self-respect, self-esteem, or self-confidence)." An employee with low emotional stability is even more vulnerable to being victimized. Despite the fact that many workplaces are becoming more knowledgeable about how trauma influences human actions and their capacity to deal with horrible feedback, many employers are still unaware of how anxiety-provoking it can be for employees (Moore, 2020).

Harsh criticism is when you express your disapproval of something solely to demonstrate that it is incorrect, untrue, misguided, senseless, disagreeable, or untrustworthy. It usually implies dissatisfaction or disagreement with something because it stresses the negative aspects of something. Negative criticism is frequently misinterpreted as a personal attack. It's possible that wasn't the purpose, but it may be perceived that way. Harsh criticism can make those who are being critiqued feel threatened or humiliated, causing them to either ignore it or react negatively to it. Much is often determined by the amount of harsh comments and the rate at which they are disseminated (Stockman et al., 2020). People can handle some bad feedback, but they may not be capable of handling large amounts of unfair feedback in one go. Harsh criticism's disadvantage is that it frequently informs individuals how much they can or should not be doing, instead of what they can or should do. As a result, it could be limiting rather than empowering. Harsh criticism, on the other hand, may be necessary to prevent a pattern of behavior that is destructive to the people involved. The current status quo may worsen if people are hesitant to express critical feedback. Harsh criticism at work has the advantage of explaining the boundaries of an idea, an action, or a circumstance in order to be practical. Harsh criticism in the workplace has gained the reputation of "being negative" in the modern workplace environment, and people who offer harsh remarks, especially to junior colleagues, are readily exploited (Fong et al., 2016).

Workplace harassment victims who are subjected to harsh criticism are less likely to be able to cope with the criticism, which is likely due to physical burnout from long hours of work, tiredness from other commitments, and mental instability (Heugten, 2011). This is sometimes cited as a contributing factor to the imbalance of power. In the event that a bullied individual was capable of ending the incident, they would do so. If they can't, something has to be done about it. You should consider the possibility that people are not actually criticizing you, but are simply disagreeing with your point of view. In many ways, we have a tendency to believe that one is always correct, and as a result, we interpret feedback as criticism (Stone \& Heen, 2015). It is possible that becoming defensive and overreacting to other workplace employees is not always a result of harsh criticism from your superiors or managers. It's also possible that a colleague is sincerely attempting to assist you, but you have become too preoccupied with your own problems to notice (Connor \& Pokora, 2017).

\section{Consequences of Workplace Harassment}

In the workplace, there is a significant cost penalty involved with harassment. With the focus placed on the long-term cost to an organization, it is anticipated that organizations will see the financial advantage of investing time and money in the avoidance of these issues. However, it seems that the majority of the overall costs associated with stress and harassment events are unlikely to be paid by the particular organization, but rather are likely to be 'externalised,' that is, dispersed among the members of the population (Levi \& Lunde-Jensen, 1995). As a result, government regulators should find the incentive for action appealing as well. According to Dorman, 2000, most people think that having a better understanding of the true consequences will have an effect on prioritization and readiness to take any action, for instance, by making funds accessible for efforts in this area (Hoel et al., 2001).

For far too long, organizations have dealt with the problem of harassment by concentrating on methods that require the least amount of effort and investment in order to merely escape liability and damage claims. When it comes to organizational health and safety in its broadest meaning, the International Labor Organization (ILO) has selected an approach that combines requests for social justice with an economic argument, or what the ILO refers to as "going the high road," as defined by the organization (Di Martino \& Pujol, 2000). For the person who has been subjected to constant harassment leading to violence, the anxiety and anguish associated with the event reflect a financial cost that is comparable to that suffered by way of lost wages. Consequently, any study of consequences should take into account both functional and symbolic consequences at the level of the person, the organization, and the broader community (Hoel et al., 2001).

Experiencing harassment or verbal abuse is likely to result in an increase in the number of sick days taken from work as a consequence of the incident (Warshaw \& Messite, 1996). The trauma they have experienced may have long-term consequences, such as being unable to return to their former 
employment and having to ultimately retire as a result of the trauma they have experienced. Although a violent harassment incident may cause the recipient to miss work, this is not always the case. Even though physical violence and the threat of physical violence are frequent occurrences among those working in the health-care industry, the vast majority of such incidents do not result in the recipient being forced to take time off from work, as is the case with criminal justice system incidents (Boyd, 1995). It is possible that extreme harassment will have an effect on absenteeism. The reason is that a person's ability to execute his or her work duties may be impaired in more severe cases of harassment because of the likely stress reaction that occurs. The majority of harassment studies before 2001, on the other hand, found only a very weak link between absenteeism and harassment. Absence from work is seen as an unproductive strategy in cases of harassment since it exacerbates an already difficult situation, according to experts. This may be one of the possible explanations (Hoel \& Cooper, 2000b).

Harassment is also likely to result in lower levels of work satisfaction and organizational commitment, both of which would be detrimental to an organization's bottom line (Barling, 1996). When considered in conjunction with the behavioral consequences mentioned above, harassment at work has the potential to reduce an individual's performance, regardless of whether they are physically assaulted, harshly verbally harassed or are just witnesses to such incidents (Afful, 2010). Furthermore, it is not impossible to suppose that third parties, who have neither seen nor been victims of harsh harassment, may be victimized themselves as well. Because of the harassment, it is possible that workplace tensions may arise between employees and their victims, or that a general climate of dread will be introduced into the office environment as a result of such harassment if it is continuous. Anecdotal research suggests that victims of harassment report lower levels of productivity at work when compared to individuals who were not tormented. Hoel and Cooper (2000a) discovered some empirical support for this by contrasting the self-rated performance of people who have been harassed with those who have not been harassed. Harassment, on the other hand, did not seem to be associated with poor job performance. Accordingly, it has been proposed that individuals who have been harassed may be more eager to show competence and dedication when their organizational position as well as their self-esteem are in jeopardy when they are bullied (Hoel et al., 1999; Hoel et al., 2020).

In certain nations, severe experiences of stress due to harassment may result in legal action. This depends on the practice and culture of the particular country. Violence, verbal and sexual and racial harassment are only a few examples of the kinds of instances that have resulted in such lawsuits. In certain nations, particularly the United States and the United Kingdom, these claims may be very expensive. There are likely to be extra expenses associated with any possible harm to the victim's public relations, in addition to any potential compensation that may be granted to the claimant (Knapp \& Kustis, 1996; Mills et al., 2019). Also, depending on the national health-care system in place, medical expenditures incurred as a result of stress, regardless of the source, may constitute a significant burden on society. In the case of physical violence, costs are likely to rise in the event of an attack that results in harm to the victim or others. This damage may be either physical or psychological in nature. For a lot of individuals, the development of post-traumatic stress disorder (PTSD) as a consequence of being exposed to an attack, verbal harassment, or sexual harassment may be very expensive, resulting in prolonged medical care or even hospitalization due to a mental collapse (Regel \& Joseph, 2017).

\section{CONCLUSION}

This study offers substantial evidence to indicate that different kinds of harassment are serious issues that impact working people all around the globe, and that this is supported by the literature. Also suggested by the study is that working environments are not free of harassment, with a significant proportion of individuals subjected to various forms of harassment on a daily basis. It is common for individuals who are exposed to different kinds of workplace harassment to suffer significant consequences, whether they were directly targeted by harassment or abuse or just saw it. The experience's ramifications are also likely to have an effect on organizations, since people who are stressed are more likely to need time off work or to be less productive while they are on the job. Workplace harassment can be visible or unnoticed, and it can also be more acceptable in society at times. Consequently, if workplace harassment receives less attention, it will become more common. This is why it's critical to speak up when the strain of harassment becomes too much to bear. Employees and victims should also understand the distinction between workplace harassment and just giving professional instructions. Someone may make a criticism "in his professional work context," which means that he is basing his opinion on his industry experience with the subject. This does not, however, imply that the judgment is constructive. When such acts become the norm due to the severity and humiliation involved, it becomes quite concerning. In the workplace, escalating disagreements with repeated harassment activities systematically directed at a particular individual should be disallowed. False allegations of blunders, aggressive scowls and other threatening nonverbal behaviors, shouting obscenities, "silent treatment," threatening to withhold resources and relevant data required for the job, and undermining sabotage and slander, are all examples of workplace harassment. The solution, in general, is constant professional learning and development for both junior and senior employees, as well as employers. 


\section{REFERENCES}

[1] Afful, C. A. (2010). Workplace bullying and its impact on productivity (Doctoral dissertation)

[2] Aguinis, H. (2019). Performance management for dummies. John Wiley \& Sons.

[3] Albrecht, S. L., Bakker, A. B., Gruman, J. A., Macey, W. H., \& Saks, A. M. (2015). Employee engagement, human resource management practices and competitive advantage: An integrated approach. Journal of Organizational Effectiveness: People and Performance.

[4] Amabile, T., \& Kramer, S. (2011). The progress principle: Using small wins to ignite joy, engagement, and creativity at work. Harvard Business Press

[5] Aquino, K., \& Thau, S. (2009). Workplace victimization: Aggression from the target's perspective. Annual review of psychology, 60, 717-741

[6] Armstrong, M. (2021). Performance management.

[7] Ashe, S., \& Nazroo, J. (2016). Equality, diversity and racism in the workplace: A qualitative analysis of the 2015 race at work survey. Report Commissioned by Business in the Community, ESRC Centre on Dynamics of Ethnicity, University of Manchester.

[8] Barling, J. (1996). The prediction, experience, and consequences of workplace violence.

[9] Bititci, U., Cocca, P., \& Ates, A. (2016). Impact of visual performance management systems on the performance management practices of organisations. International Journal of Production Research, 54(6), 1571-1593.

[10] Bonnet, M. H., \& Arand, D. L. (2010). Hyperarousal and insomnia: state of the science. Sleep medicine reviews, 14(1), 9-15.

[11] Boyd, N. (1995). Violence in the workplace in British Columbia: A preliminary investigation. Canadian Journal of Criminology, 37(4), 491-519.

[12] Chin, H., \& Yi, M. Y. (2019, May). Should an Agent Be Ignoring It? A Study of Verbal Abuse Types and Conversational Agents' Response Styles. In Extended Abstracts of the 2019 CHI Conference on Human Factors in Computing Systems (pp. 1-6)

[13] Clark, D. A., \& Beck, A. T. (2011). The anxiety and worry workbook: the cognitive behavioral solution. Guilford Press.

[14] Connor, M., \& Pokora, J. (2017). EBOOK: Coaching and Mentoring at Work: Developing Effective Practice: Developing Effective Practice. McGraw-Hill Education (UK).

[15] De las Casas, S. P. B. (2018). Psychological harassment in the workplace and the right to work in dignity: A comparative review of the laws in Colombia, Peru, United Kingdom and the United States. ILSA J. Int'l \& Comp. L., 25, 465.

[16] DEBO, R., \& GARY, A. (1996). The real "disclosure": Sexual harassment and the bottom line. Sexual harassment in the workplace, 5,199

[17] Di Martino, V., \& Pujol, J. (2000). The SafeWork Training Package on Drugs and Alcohol, Violence, Stress, Tobacco and HIV/AIDS. International Labour Organisation Working Paper.

[18] Einarsen, S. V., Hoel, H., Zapf, D., \& Cooper, C. L. (2020). The concept of bullying and harassment at work: The European tradition. In Bullying and harassment in the workplace (pp. 3-53). CRC press.

[19] Einarsen, S. V., Hoel, H., Zapf, D., \& Cooper, C. L. (2020). The concept of bullying and harassment at work: The European tradition. In Bullying and harassment in the workplace (pp. 3-53). CRC press

[20] Fong, C. J., Warner, J. R., Williams, K. M., Schallert, D. L., Chen, L. H., Williamson, Z. H., \& Lin, S. (2016). Deconstructing constructive criticism: The nature of academic emotions associated with constructive, positive, and negative feedback. Learning and Individual Differences, 49, 393-399.

[21] Giorgi, G., Perminienè, M., Montani, F., Fiz-Perez, J., Mucci, N., \& Arcangeli, G. (2016). Detrimental effects of workplace bullying: impediment of self-management competence via psychological distress. Frontiers in psychology, 7, 60

[22] Grenny, J. (2014). The best teams hold themselves accountable. Harvard Business Review.

[23] Hansen, A. M., Hogh, A., \& Persson, R. (2011). Frequency of bullying at work, physiological response, and mental health. Journal of psychosomatic research, 70(1), 19-27.

[24] Hoel, H., \& Cooper, C. L. (2000). Destructive conflict and bullying at work. Manchester: Manchester School of Management, UMIST.

[25] Hoel, H., Cooper, C. L., \& Einarsen, S. V. (2020). Organizational effects of workplace bullying. In Bullying and Harassment in the Workplace (pp. 209-234). CRC Press.

[26] Hoel, H., Cooper, C. L., Kemshall, H., \& Pritchard, J. (2000). Victims of workplace bullying. In Good practice in working with victims of violence. Jessica Kingsley Publishers.

[27] Hoel, H., Sparks, K., \& Cooper, C. L. (2001). The cost of violence/stress at work and the benefits of a violence/stress-free working environment. Geneva: International Labour Organization, 81

[28] Hollenbeck, J. R., \& Jamieson,B. B. (2015). Human capital, social capital, and social network analysis: Implications for strategic human resource management. Academy of management perspectives, 29(3), 370-385

[29] Holman, D., Chissick, C., \& Totterdell, P. (2002). The effects of performance monitoring on emotional labor and well-being in call centers. Motivation and Emotion, 26(1), 57-81.

[30] Hubert, A. and van Veldhoven, M. (2001). Risk sectors for undesirable behaviour and mobbing. European Journal of Work and Organizational Psychology, 10, pp. 415- 424.

[31] Keashly, L. and Harvey, S. (2006). Workplace emotional abuse. In E. Kelloway, J. Barling and J. Hurrell (eds), Handbook of Workplace Violence. Thousand Oaks, CA: Sage Publications, pp. 95- 120.

[32] Keashly, L., \& Jagatic, K. (2011). North American perspectives on hostile behaviors and bullying at work. Bullying and harassment in the workplace: Developments in theory, research, and practice, 2, 41-71

[33] Killoren, R. (2014). The toll of workplace bullying. Research management review, 20(1), n1

[34] Levi, L., Lunde-Jensen, P., \& European Foundation for the Improvement of Living and Working Conditions. (1996). A model for assessing the costs of stressors at national level: Socioeconomic costs of work stress in two EU member states. Office for official publications of the European communities.

[35] Lewis, D. and Gunn, R. (2007). Workplace bullying in the public sector: understanding the racial dimension. Public Administration, 83, pp. 641- 665.

[36] Leymann, H. (1996). The content and development of mobbing at work. European Journal of Work and Organizational Psychology, 5, pp. 165- 184.

[37] Lockwood, G. (2008). A legal analysis of sexual harassment employment tribunal cases 1995-2005. International Journal of Law and Management.

[38] Lutgen-Sandvik, P., \& McDermott, V. (2008). The constitution of employee-abusive organizations: A communication flows theory. Communication Theory, 18(2), 304-333

[39] Martin, K., \& Freeman, R. E. (2003). Some problems with employee monitoring. Journal of Business Ethics, 43(4), 353-361

[40] Mills, C. B., Keller, M., Chilcutt, A., \& Nelson, M. D. (2019). No laughing matter: Workplace bullying, humor orientation, and leadership styles. Workplace health \& safety, 67(4), 159-167.

[41] Mone, E. M., \& London, M. (2018). Employee engagement through effective performance management: A practical guide for managers. Routledge.

[42] Niedhammer, I., Chastang, J. F., Sultan-Taïeb, H., Vermeylen, G., \& Parent-Thirion, A. (2013). 
[43] Psychosocial work factors and sickness absence in 31 countries in Europe. The European Journal of Public Health, 23(4), 622-629.

[44] Nielsen, M. B., Indregard, A. M. R., \& Øverland, S. (2016). Workplace bullying and sickness absence: a systematic review and meta-analysis of the research literature. Scandinavian journal of work, environment \& health, 359-370.

[45] Nielsen, M. B., Matthiesen, S. B., \& Einarsen, S. (2010). The impact of methodological moderators on prevalence rates of workplace bullying. A meta-analysis. Journal of Occupational and organizational Psychology, 83(4), 955-979.

[46] Nielsen, M. B., Notelaers, G., \& Einarsen, S. (2011). Measuring exposure to workplace bullying. Bullying and harassment in the workplace: Developments in theory, research, and practice, 2 , 149-174.

[47] Nielsen, M. B., Pallesen, S., Harris, A., \& Einarsen, S. V. (2018). Protocol for a systematic review and meta-analysis of research on the associations between workplace bullying and sleep. Systematic reviews, 7(1), 1-7.

[48] Nielsen, M. B., Tvedt, S. D., \& Matthiesen, S. B. (2013). Prevalence and occupational predictors of psychological distress in the offshore petroleum industry: a prospective study. International archives of occupational and environmental health, 86(8), 875-885

[49] Productivity Commission. (2010). Performance benchmarking of Australian business regulation: Occupational health \& safety. Productivity Commission.

[50] Quigg, A. M. (2016). Bullying in the arts: vocation, exploitation and abuse of power. Routledge.

[51] Regel, S., \& Joseph, S. (2017). Post-traumatic stress. Oxford University Press.

[52] Schütte, S., Chastang, J. F., Malard, L., Parent-Thirion, A., Vermeylen, G., \& Niedhammer, I. (2014). Psychosocial working conditions and psychological well-being among employees in 34 European countries. International archives of occupational and environmental health, 87(8), 897-907.

[53] Spielman, A. J., Caruso, L. S., \& Glovinsky, P. B. (1987). A behavioral perspective on insomnia treatment. Psychiatric Clinics of North America, 10(4), 541-553.

[54] Stockman, S., Van Hoye, G., \& da Motta Veiga, S. (2020). Negative word-of-mouth and applicant attraction: The role of employer brand equity. Journal of Vocational Behavior, 118, 103368.

[55] Stone, D., \& Heen, S. (2015). Thanks for the feedback: The science and art of receiving feedback well (even when it is off base, unfair, poorly delivered, and frankly, you're not in the mood). Penguin

[56] Tehrani, N. (2004). Bullying: a source of chronic post-traumatic stress?. British journal of guidance \& counselling, 32(3), 357-366.

[57] Tepper, B. J., Mitchell, M. S., Haggard, D. L., Kwan, H. K., \& Park, H. M. (2015). On the exchange of hostility with supervisors: An examination of self-enhancing and self-defeating perspectives. Personnel Psychology, 68(4), 723-758

[58] Tomczak, D. L., Lanzo, L. A., \& Aguinis, H. (2018). Evidencebased recommendations for employee performance monitoring. Business Horizons, 61(2), 251-259.
[59] Van Heugten, K. (2011). Social work under pressure: How to overcome stress, fatigue and burnout in the workplace. Jessica Kingsley Publishers.

[60] Verkuil, B., Atasayi, S., \& Molendijk, M. L. (2015). Workplace bullying and mental health: a meta-analysis on cross-sectional and longitudinal data. PloS one, 10(8), e0135225.

[61] Wagner, J. A., \& Hollenbeck, J. R. (2020). Organizational behavior: Securing competitive advantage. Routledge

[62] Warshaw, L. J., \& Messite, J. (1996). Workplace violence: preventive and interventive strategies. Journal of Occupational and Environmental Medicine, 38(10), 993-1006.

[63] Weinberg, A., Bond, F., Cooper, C., \& Sutherland, V. J. (2010). Organizational stress management: A strategic approach. Palgrave Macmillan.

[64] Williams, H. (2001). Maintaining a harassment-free workplace.

[65] World Health Organization. (2009). Comparative Quantification of Health Risks. Geneva: World Health Organization; 2004.

[66] Zafar, W., Khan, U. R., Siddiqui, S. A., Jamali, S., \& Razzak, J. A. (2016). Workplace violence and self-reported psychological health: coping with post-traumatic stress, mental distress, and burnout among physicians working in the emergency departments compared to other specialties in Pakistan. The Journal of emergency medicine, 50(1), 167-177

[67] Zapf, D., Escartin, J., Scheppa-Lahyani, M., Einarsen, S. V., Hoel, H., \& Vartia, M. (2020). Empirical findings on prevalence and risk groups of bullying in the workplace. In Bullying and harassment in the workplace (pp. 105-162). CRC Press

[68] Zhao, W., Lun, R., Gordon, C., Fofana, A. B. M., Espy, D. D., Reinthal, M. A., ... \& Luo, X. (2016). A human-centered activity tracking system: Toward a healthier workplace. IEEE Transactions on Human-Machine Systems, 47(3), 343-355.

Internet References

[69] HM Courts \& Tribunals Service \& Employment Tribunal, (2021). Mrs Carol Hurley v East Sussex Healthcare NHS Trust: 2300231/2019. Employment Tribunal decision. GOV.UK. https://www.gov.uk/employment-tribunal-decisions/mrs-carolhurley-v-east-sussex-healthcare-nhs-trust-2300231-slash-2019

[70] Moore, R. (2020). Handling Harsh Criticism In The Workplace: How To Stay Resilient Under Immense Pressure. Forbes. https://www.forbes.com/sites/forbesbusinessdevelopmentcouncil/2 021/08/04/15-mistakes-leaders-often-make-when-implementingtech-into-the-sales-process/?sh=41d8fe1a4377

[71] Pghrevent Violence at Work. Verbal Abuse. http://www.prevention-violence.com/en/int-151.asp\#haut

[72] Rodela, J. (2015). How Excessive Performance Monitoring Can Suck the Life Out of Your Agents. Your Australian Call Centre Partner in the Philippines. SelectVoiceCom https://turtler.io/news/16-worst-and-most-extreme-waysemployers-are-spying-on-their-people

[73] Wishnia, J. (2020). Are Verbal Threats Assault? legal Match https://www.legalmatch.com/law-library/article/verbal-threats-asassault.html 